\title{
Östrogeniale Notlösung?
}

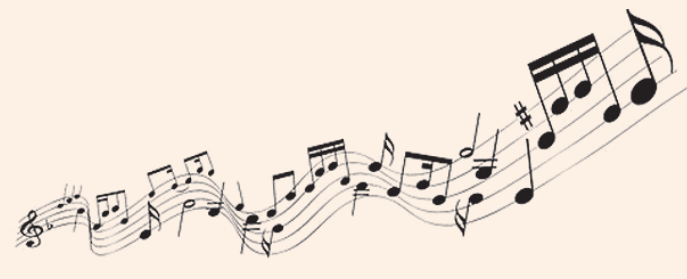

Bernhard Gurtner

Korrespondenz:

Dr. med. Bernhard Gurtner Eggstrasse 76 CH-8620 Wetzikon

gurtner.bernhard@bluewin.ch
Der Präsident (69) des gemischten Chores von Oberchnorzwilen hat schlaflose Nächte. Stundenlang wälzt er sich gequält und zutiefst unhappy auf seinem Bett. Dösend kommen ihm phantastische Ideen, die er schon bei der nächsten Rotation seines müden Körpers verwirft oder im trüben Schein des Nachttisch-Lämpchens auf einem bereitgelegten Zettel notiert. Bei hellerem Morgenlicht besehen erweisen sich aber die zittrig hingekritzelten Stichwörter als unnütze Hirngespinste.

Die Krise war absehbar und hat nicht nur die Oberchnorzwiler Singgemeinschaft erfasst. Konzertfotos in der Regionalzeitung zeigen bei allen Chören von Jahr zu Jahr mehr weissen Belag auf den Häuptern der Sänger und Sängerinnen - wie grau gewordenen Schnee auf den Gipfeln der Glarner Alpen. Da hilft es nicht viel, wenn sich einige Damen die Haare dunkel färben lassen und bunte Halsschleifen umlegen. Es lässt sich kein Nachwuchs mehr finden, vor allem fehlen kraftvolle Tenöre.

Im Oberchnorzwiler Chor ist die Lage besonders schlimm. Nachdem der kurzatmig gewordene Toni zum Bass versetzt werden musste, sind als Tenöre nur noch Bruno, Urs und Otti verblieben. Tapfer versuchen die drei Veteranen, sich von den in ihrem Rücken orgelnden Bässen und den dominierenden Frauen stimmlich abzuheben. Doch Bruno muss ab der obersten Notenlinie zur näselnden Kopfstimme wechseln und auch Urs verspürt im musikalischen Dachgeschoss etwas Höhenangst. Wie heisere Jodler erklimmen sie die steilen Gipfel der Melodien.

Ja, könnte man nicht einige der in unserem Land noch zahlreichen jungen Jodler als Tenöre abwerben, um überalterten Chören eine Blutauffrischung zu verschaffen? Als Anreiz müssten wohl Transfersummen wie bei Fussballstars vereinbart werden. Wer soll sie bezahlen, nachdem die Kollekte beim letzten Konzert in der Turnhalle so wenig eingetragen hat? Brächte man bodenständige Jodler dazu, beim Singen die Hände aus den Hosentaschen zu ziehen, damit sie die Notenblätter halten können? Können die überhaupt Musiknoten lesen? Rasch erstickt der Präsident die untaugliche Idee im zerwühlten heissen Kopfkissen.

Im Sängerblatt war kürzlich zu lesen, dass sich alternde Spitzentenöre bei Professor Rima Glottidis in Ohio mit einem ambulanten Eingriff die Stimmbänder raffen lassen, um weiterhin mit höchsten Tönen brillieren zu können. Für einen Pavarotti mag ein «voice lifting» bezahlbar sein, doch für Bauer Otti ...? Die Gedanken schweifen ab zu den Sängerknaben, die man einst ohne Betäubung kastriert hat, um den Stimmbruch $\mathrm{zu}$ verhindern. Viele starben an Infektionen, andere überlebten als körperliche und seelische Krüppel, denn nicht jeder wurde so berühmt wie Farinelli im 18. Jahrhundert, der mit seiner Kastratenstimme mehr als drei Oktaven beherrschte und die Musikfreunde der europäischen Hauptstädte in Ekstase versetzte.

Da dämmert es dem schlaflosen Präsidenten: Wenn männliches Testosteron in der Pubertät die Stimme in den Keller fallen lässt, könnte man da nicht mit weiblichen Hormonen Gegensteuer geben, brodelnde Bässe in weiche Tenöre umwandeln? Seit die Frauenärzte Östrogene nicht mehr gegen Menopausebeschwerden und Osteoporose empfehlen, liegen noch in manchen Hausapotheken ungebrauchte Hormonpflaster. Den Präsidenten, der gerne mit gutem Beispiel vorangehen möchte, schaudert aber der Gedanke, sich selbst regelmässig ein Pflaster anzukleben. Auf die tägliche Bartrasur würde er gerne verzichten, doch könnten vielleicht auch seine Brüste weibliche Formen annehmen. Stöhnend befreit sich der geplagte Mann von diesem Alptraum und zieht seine restless legs an sich wie ein Embryo.

Wenn sich weiterhin kein Nachwuchs einstellt, wird man einige Alt-Sängerinnen zu den Tenören umteilen müssen. Der Not gehorchend haben das auch andere Chöre schon getan. Eine anpassungsfreudige Tenorette wurde bald zur Stimmführerin, weil sie ab Blatt singen konnte und alles viel rascher auswendig wusste. Das habe die Gruppenharmonie ungünstig beeinflusst.

Noch ein tiefer Seufzer: In zwei Tagen muss das verdiente Chormitglied Michael (84) zu Grabe getragen werden. Abdankungen folgen sich in immer kürzeren Abständen, begleitet von einem stets dünner klingenden letzten Sängergruss. Mit der Vermutung, dass sich junge Männer heute eher für Bank- als für Musiknoten interessieren und lieber singeln als singen, gleitet der erschöpfte Chorpräsident gegen Morgen doch noch in einen alle Sorgen vernebelnden Schlummer. Er träumt vom Wolf, der Kreide gefressen hat, um Rotkäppchen mit einer helleren Stimme zu täuschen. 